\title{
El botón de nácar e a repressão na América Latina
}

\author{
Moisés Carlos Ferreira*
}

Resumo: O artigo traz algumas reflexões sobre os conteúdos históricos do documentário $O$ botão de pérola (El botón de nácar, Espanha/ França/ Chile/ Suíça, 2015), de Patricio Guzmán e objetiva expor, de forma crítica, as raízes da subalternidade e as modalidades de repressão exercidas na América Latina. Para tal, este documentário será aqui abordado como uma metáfora da violência cultural, política e econômica construídas nesta parte do continente americano.

Palavras-chave: documentário; colonialidade; neoliberalismo; pós-colonialidade.

Resumen: El artículo trae algunas reflexiones sobre los contenidos históricos del documental El botón de nácar (España/ Francia/ Chile/ Suiza: 2015), de Patricio Guzmán y pretende exponer, de forma crítica, las raíces de la subalternidad y las modalidades de represión ejercidas en América Latina. Para ello, este documental será aquí abordado como una metáfora de la violencia cultural, política y económica construidas en esta parte del continente americano.

Palabras clave: documental; colonialidad; neoliberalismo; poscolonialidad.

\begin{abstract}
This paper presents some considerations about the historic contents of the documentary The pearl button (El botón de nácar, Spain/ France/ Chile/ Switzerland, 2015) by Patricio Guzmán and its objective is to make clear, in a critique way, the roots of subalternity and the sorts of repression performed in Latin America. In order to do that, the documentary will be regarded here as a metaphor of the cultural, political and economic violence constructed at this part of the American continent.
\end{abstract}

Keywords: documentary; colonialiality; neoliberalism; post-colonialiality.

Résumé : Cet article questionne le contenu du documentaire historique Le bouton de nacre (El botón de nácar, de Patricio Guzmán. Espagne / France / Chili / Suisse : 2015) et vise à exposer, de façon critique, les racines de la subordination et les méthodes répressives pratiquées en Amérique latine. À cette fin, ce documentaire sera abordé ici comme une métaphore des violences culturelles, politiques et économiques qui ont été faites dans cette partie du continent américain.

Mots-clés : documentaire ; colonialité ; néolibéralisme ; post-colonialisme.

\footnotetext{
* Doutorando. Pontifícia Universidade Católica - PUC-SP, Programa de PósGraduação em História Social, Centro de Estudos de História da América Latina CEHAL. Bolsista CAPES. 05014-901, São Paulo, Brasil. E-mail: terraemar@gmail. com
}

Submissão do artigo: 26 de maio de 2017. Notificação de aceitação: 22 de julho de 2017.

Doc On-line, n. 22, setembro de 2017, www.doc.ubi.pt, pp. 295-307. 


\section{$[\ldots]$}

Eu não venho cantar o esplendor de Machu Picchu, a Grande Cordilheira e a neve eterna; não venho cantar esta América de vulcões e arquipélagos, esta América altiplânica da lhama esbelta e da vicunha; venho em nome de uma América parda, branca e negra, e desde Arauco a Yucatán, venho em nome desta América indígena agonizante, venho sobretudo em nome de uma América proletária em nome do cobre e do estanho ensanguentado.

$[\ldots]$

Manoel de Andrade - Ai, América, que longo caminhar!

A produção cinematográfica que ilustra este texto é o documentário $\mathrm{O}$ botão de pérola, com o título original em espanhol El botón de nácar, que foi dirigido e produzido pelo respeitado documentarista chileno Patricio Guzmán. ${ }^{1}$ Essa obra cinematográfica foi uma coprodução entre Espanha, França, Chile e Suíça, realizada pela produtora Atacama Production em 2015.

Este artigo apresenta uma análise do documentário e o discute à luz de teóricos que tratam da colonialidade e modernidade criticando a preservação da ótica de mundo pautada em valores europeus. Os estudiosos que embasaram as reflexões aqui apresentadas são os latino-americanos Mignolo (2003) e Quijano (2005), pesquisadores fundamentais do pensamento pós-colonialista.

A escolha por esse filme deve-se à sua sensibilidade em tratar de assuntos caros à História da América Latina, especialmente à do Chile. No enredo, há duas narrativas - a política e a cultural - que se entrecruzam em momentos históricos do país.

Dois fatos históricos importantes que são abordados por esse documentário: o primeiro é o processo de ocupação das terras da América do Sul, exploradas para satisfazer os interesses mercantis europeus, conforme estudo de Mignolo:

O ocidentalismo e não o colonialismo foi a principal preocupação, primeiro, da coroa espanhola e dos letrados durante os séculos XVI e XVII e, segundo, do estado e dos intelectuais durante o período da construção das nações, que definiu América Latina em sua diferença em relação á Europa e ao ocidente. (Mignolo, 2003: 138).

Ainda, de acordo com Mignolo (2003), pode-se encontrar no documentário a presença de uma razão subalterna, que configura-se quando os conheci-

1. Patricio Guzmán es uno de los cineastas chilenos de mayor reconocimiento internacional. Después del golpe de estado permaneció en el Estadio Nacional de Santiago, incomunicado y amenazado de fusilamiento. Abandonó Chile en noviembre de 1973. Ha vivido en Cuba, España y Francia, donde reside. Seis de sus obras han sido estrenadas en Cannes, entre las que sobresalen La Batalla de Chile, El Caso Pinochet, Salvador Allende y Nostalgia de la Luz. Con esta última recibió el Gran Premio otorgado por la Academia del Cine Europea en 2010. Su última obra El Botón de Nácar obtuvo el Oso se Plata en Berlín en 2015. Fue invitado a formar parte de la Academia de Hollywood en 2013. Es presidente y fundador del Festival Documental de Santiago, FIDOCS. Retrospectivas recientes: British Film Institute, Harvard Film Archive. Fonte:Patricio Gusmán. Disponível em: www.patricioguzman.com/es 
mentos locais são negados, subsumidos a um sistema de verdade que se propõe como universal e não admite questionamentos ou variantes nem um novo dogma, tal qual o ideário cristão medieval, pois a razão subalterna é aquilo que surge como resposta à necessidade de repensar e reconceitualizar as histórias que são narradas. A conceitualização é apresentada para dividir o mundo entre regiões e povos cristãos e pagãos, civilizados e bárbaros, modernos e prémodernos, desenvolvidos e subdesenvolvidos, todos eles projetos globais que mapeiam a diferença colonial.

O segundo fato do documentário que será aqui analisado diz respeito aos interesses de diversos grupos sociais quanto à implementação das ditaduras militares no cone sul do continente americano. No caso chileno, não se pode olvidar o papel dos "Chicago boys" ${ }^{2}$ - jovens economistas que estudaram nos Estados Unidos e aplicaram no Chile uma série de medidas econômicas logo após o golpe de estado de 1973.

Naquele momento, o governo de Augusto Pinochet aproveita o choque em que as pessoas estavam vivendo para aplicar as seguintes medidas: flexibilização da economia; desregulamentação das leis trabalhistas; enxugamento do estado; fragilização dos sindicatos; supressão do controle de preços; privatização de empresas estatais; eliminação de importações e redução dos gastos públicos.

Tais decisões econômicas, que ampliaram os privilégios do grande capital, foram baseadas em diretrizes neoliberais e elogiadas pessoalmente pelo grande mentor do neoliberalismo da época, Milton Friedman (1912-2006), professor de Economia da Universidade de Chicago que orientou os alunos chilenos quando lá estudaram. Essas medidas não provocaram a estabilização econômica, mas geraram maior concentração de renda nas mãos dos mais ricos, ampliando os gastos dos mais pobres.

Para manter esse plano econômico, fez-se necessário o uso da força - chamado de doutrina de choque e pavor - que consistiu no emprego da violência, do terrorismo de estado, dos desaparecimentos, da guerra psicológica, das torturas e perseguições aos chamados inimigos internos do estado chileno.

A análise de Anderson colabora para esclarecer tais medidas:

Refiro-me, bem entendido, ao Chile sob a ditadura de Pinochet. Aquele regime tem a honra de ter sido o verdadeiro pioneiro do ciclo neoliberal da história contemporânea. O Chile de Pinochet começou seus programas de maneira dura: desregulação, desemprego massivo, repressão sindical, redis-

2. Nos anos de 1950, uma das medidas do desenvolvimento econômico chileno foi estabelecer um convênio entre a Universidade Católica do Chile e a Universidade de Chicago para enviar alunos chilenos para estudar o modelo de econômico liberal na universidade americana. O departamento de Economia da Universidade Católica do Chile converteu-se em uma sucursal da Universidade de Chicago. 
tribuição de renda em favor dos ricos, privatização de bens públicos. Tudo isso foi começado no Chile, quase um decênio antes de Thatcher, na Inglaterra. (Anderson, 1995: 18).

De acordo com o estudioso, percebe-se que o Chile serviu de laboratório para as medidas econômicas neoliberais que foram implementadas em outros países ocidentais nas décadas subsequentes, carregando novas formas de dominação, por meio da hegemonia econômico-cultural, propalada pelos grandes meios de comunicação e organismos internacionais. Esse modelo econômico foi também uma solução para muitos países na América Latina a partir dos anos de 1990, conforme pode-se ler em Mignolo:

Bajo el hechizo del neoliberalismo y la magia de los medios de comunicación que lo promueven, la modernidad y la modernización, junto con la democracia, se venden como un paquete de viaje a la tierra prometida de la felicidad, un paraíso donde, por ejemplo, cuando usted ya no puede comprar la tierra porque la tierra es limitada y no producible o está monopolizada por quienes tienen el control y la concentración de la riqueza puede comprar la tierra virtual. Sin embargo, cuando la gente no compra el paquete o tiene otras ideas de cómo la economía y la sociedad deben ser organizadas, se va a ver convertida en sujetos de todo tipo de violencia directa e indirecta. (Mignolo, 2010: 09).

Tal solução se coloca também como um paradigma, ancorado em um conhecimento racional, que, por ser produzido discursivamente, adquiriu status de verdade. Com base em Mignolo (2010), há um discurso disseminado que naturaliza a modernidade como um processo universal e o único ponto de chegada, que oculta seu lado de reprodução frequente da colonialidade.

Desse modo, o discurso colonial e pós-colonial incita a questionar os sujeitos para além dos estereótipos e do fetichismo, pois a necessidade do fetiche se expandiu, por intermédio de suas verdades e seus aparatos, como a crença nos mitos do progresso e Estado Nação, a ode à democracia, ao estado de direito e o endeusamento aos ícones como liberdade, igualdade e fraternidade, juntamente com a submissão e a tutela do mercado.

$O$ botão de pérola, arte em linguagem cinematográfica que traz à tona diversos discursos, torna possível que esses questionamentos sejam suscitados.

Para análise do documentário, faz-se necessário observar, inicialmente, seu título, que apresenta a palavra botão, que em termos botânicos indica um estado antes de desabrochar, desenvolver. Cada desabrochar da pérola será abordado em temporalidades distintas na história chilena e em ambas as temporalidades serão tratadas como uma alegoria da violência e da lógica do extermínio.

Por meio de reflexões e conflitos que são apresentados no documentário de maneira poética, nota-se uma metáfora: o uso da água e como esta é guardiã da memória e também cemitério, já que este recurso natural permeia a história 
dos povos nômades das águas, que serão apresentados pelo documentário. A citação a seguir, retirada do site chileno CineChile - Enciclopedia Del Cine Chileno, especializado em cinema, colabora para elucidar o filme:

El océano contiene la historia de la humanidad. El mar guarda todas las voces de la tierra y las que vienen desde el espacio. El agua recibe el impulso de las estrellas y las transmite a las criaturas vivientes. El agua, el límite más largo de Chile, también guarda el secreto de dos misteriosos botones que se encuentran en el fondo del océano. Chile, con sus 2670 millas de costa y el archipiélago más largo del mundo, presenta un paisaje sobrenatural. En ella están los volcanes, montañas y glaciares. En ella están las voces de los indígenas patagones, los primeros marineros ingleses y también los prisioneros políticos. Se dice que el agua tiene memoria. Este film muestra que también tiene una voz. ${ }^{3}$

A água, nesse sentido, representa o fio condutor da trama, e o botão representa a violência perpetrada pelos povos colonizadores.

Em relação à linguagem cinematográfica, sabe-se que ela possui o poder mimético, de imagem em movimento, que não apenas copia a realidade, mas a interpreta, a questiona, a reproduz pelo olhar do diretor, pois, de acordo com Santos (2011):

[...] No caso específico do cinema, distintas relações do sujeito com a imagem fílmica podem ocorrer, tais como acolhida, ruptura, repulsa, conformidade, identificação, resistência, introjeção, críticas ou combinação de várias delas. Nesse processo de interação com as imagens, há sempre o investimento de emoções. (Santos, 2011: 7).

Além dessas possibilidades de interação entre sujeito e cinema, a sétima arte pode ser vista também como uma representação do passado e objeto de pesquisa histórica, capaz de questionar um passado próximo ou longínquo, resgatar a memória de personagens envolvidos e, de acordo com Villaça (2015), "à arte cabe não se limitar à mera representação do fato histórico, mas elaborar uma reflexão sobre ele". Percebe-se, portanto, que a narrativa de $O$ botão de pérola não se pauta apenas na representação de fatos históricos, mas na possibilidade de criticá-los e reinterpretá-los, por exemplo, na citação acerca do contato de europeus com os povos da Patagônia ou na explicação dada às formas de extermínio durante a ditadura militar chilena.

Outra característica do documentário é recuperar diversos episódios históricos em temporalidades distintas - o que o configura como documentário de representação social, conforme definição de Nichols (2009: 26).

Um desses episódios reporta ao século 19, quando um jovem nativo, pertencente a um dos grupos étnicos da Patagônia, foi levado para a Inglaterra em 3014.

3. CineChile: Enciclopedia del cine chileno. Disponível em: http://cinechile.cl/pelicula- 
troca de um botão de pérola, durante as novas formas de ocupação das terras meridionais da América do Sul.

Com a chegada de missionários religiosos e fazendeiros criadores de gado, àquela época o processo de aniquilamento dos povos nativos é acelerado, segundo documento da Biblioteca Nacional do Chile, sobre memória chilena.

El interés de los europeos no se agotó en las riquezas que podían encontrar en el nuevo mundo. También el conocimiento científico motivó a algunos hombres de ciencia a explorar parte del territorio chileno durante los siglos coloniales. John Byron, George Vancouver y James Cook, entre otros, aportaron interesantes conocimientos geográficos y cartográficos sobre Chile y América meridional. También durante el siglo XIX, llegó a América un número significativo de viajeros ingleses. Estos fueron contratados por los gobiernos sudamericanos y viajaron motivados por el afán científico y el desarrollo industrial y comercial que se afianzaba en la región. ${ }^{4}$

Quando o jovem nativo chegou às terras europeias, recebeu o nome inglês de Jimmy Button, em referência ao botão de pérola pelo qual foi trocado. Ele viveu na Inglaterra por um determinado período, porém, ao voltar para sua região, já europeizado, não mais se identificou como pertencente à sua cultura e tão pouco era visto como inglês - um típico exemplo do processo de aculturação ali imposto e o claro reconhecimento de superioridade de um grupo em relação à inferioridade do outro. Um se constrói à medida que subalterna o outro. ${ }^{5}$

O documentário vai revelando como se deu o contato dos "povos das águas", ou seja, dos habitantes das terras que vieram a ser chamadas de Patagônia ocidental com os conquistadores espanhóis a partir do século XVI. Cabe lembrar que o nome Patagônia é derivado da palavra patacones, que significa pessoa alta e com pés grandes. Essa era a imagem que os espanhóis fizeram dos habitantes dessa região na época que lá chegaram. Isso pode ser um sinal de como os europeus imaginavam os nativos - como seres monstruosos e não humanos, demonstrando a "superioridade europeia".

Ao elucidar o contato entre culturas díspares, a europeia e a indígena, a narrativa mostra como ocorreu esse intercambio cultural que provocou o extermínio da população que lá habitava, em nome da civilização europeia e de seu ideário cristão.

Os povos Kawésgar, conhecidos também como Alacalufes, são uns dos povos originários da cultura chilena. Segundo Emperaire (2002), os Kawésgar

4. Memoria chilena-Biblioteca Nacional do Chile. Disponível em: www.memoriachilena. cl/602/w3-article-619.html

5. Essa tentativa "civilizatória", que foi imposta por "intercâmbio cultural" ou até mesmo mascarada pelo "apreço ao exótico" aconteceu em outras localidades coloniais, vide o caso de Sarah Baartman, da África do Sul, que também ocorreu no início do século XIX, retratada no filme Vênus negra, de Abdellatif Kechiche. França/ Bélgica: 2010. 
eram caçadores e coletores. Viviam no sul do Chile, na Patagônia ocidental, entre o golfo de Penas e o Estreito de Magalhães, região com grande número de pequenas ilhas, canais e fiordes e com baixas temperaturas. Esses povos eram nômades e tinham uma dieta alimentar baseada em peixes, mariscos, carne de lontra, lobo marinho e focas. Manuseavam pedras, ossos, madeiras, conchas de mariscos, peles de lontra e de foca e também fibras vegetais e com estes últimos materiais confeccionavam canoas, arcos, flechas, arpões, facas e cestos.

Com base em entrevistas e no uso da história oral de diversos remanescentes dessa etnia, o documentário deixa explícita a atávica relação dominaçãoresistência. Tal relação vigora desde os tempos coloniais até atualidade e possui expressões em formas de violência - do extermínio físico à aculturação determinada pela penetração de padrões culturais que subsumem as identidades originárias dos povos nativos deste continente.

Assim, pode-se afirmar que para explicitar a relação dominação-resistência, a película vai descortinando as manifestações de resistências dos Kawésgar, a começar pelo fato de eles não se identificarem com o conceito de cidadania chilena, recusando a subjugação ao estado chileno e seus saberes, o que pode ser visto como uma forma de preservar seus padrões de produção de sentidos e seu universo simbólico.

Dessa forma, compreende-se que a resistência dos povos Kawésgar se dá de ao manterem vivas sua cultura e sua língua, mesmo com o processo de colonização impetrado pelos europeus.

Outro momento que reflete a resistência dos kawésgar é a entrevista, feita em voz-off pelo diretor Patricio Guzmán, da remanescente dessa etnia, Gabriela Paterito. Quando o diretor lhe pede para que ela traduza algumas palavras, como "água", "praia", "tormentas", de sua língua nativa para o espanhol, ela as traduz, pois tais vocábulos fazem parte de seu universo, de seu conhecimento de mundo. Contudo, quando ele pede que ela traduza palavras como "polícia" e "deus", a remanescente não consegue traduzi-las, explicando que tais palavras não existem em sua língua. Esse impasse linguístico revela que ainda há distinção social e simbólica entre a cultura dos kawésgar com os valores europeus modernos.

Outra manifestação dessa resistência dos povos nativos é quando Gabriela Paterito afirma que ela não se sente chilena e que não possui a identidade desse estado nacional. Gabriela mantém vivas suas tradições, sua cultura, suas memórias e com isso preserva a forma identitária de seu grupo de origem.

Observa-se que há uma dualidade conflitante na relação entre colonizador e colonizado: de um lado há uma dominação pautada por genocídios e etnocí- 
dios; de outro, há as práticas sociais dos povos que se reafirmam como seres integrados e pertencentes à natureza, e que mantêm viva sua cultura.

A abordagem histórica sobre as faces da violência no Chile faz, também, uma análise dos massacres ocorridos pelos exploradores europeus nos séculos passados, principalmente no período de colonização desse território. A época foi marcada por embates entre os colonizadores europeus e os povos originários do sul do Chile - o que gerou o extermínio de alguns povos e a aculturação de outros pela cultura europeia ali implementada. Esses massacres são comparados no filme com as práticas repressivas engendradas em território chileno durante a brutal ditadura militar entre os anos de 1973 a 1990, como demonstra Dinges:

[...] com o golpe, Pinochet ganhou a reputação de uma espécie de anjo vingador anticomunista. Com agressão e brutalidade nunca vistas na América do Sul, ele dizimou o maior e mais bem organizado efetivo esquerdista da região. Agiu primeiro com prisões em massa, campos de concentração e execuções sumárias nos dias e semanas que seguiram ao golpe. Depois passou à tarefa mais árdua de erradicar os grupos de oposição clandestinos. (Dinges, 2005: 32-33).

Para representar essa violência institucionalizada, cometida pela ditadura, o diretor do filme apresenta um botão novamente, só que, dessa vez, o de roupa. Esse botão, retirado das águas do Oceano Pacífico, perto da costa chilena, revela vestígios das roupas de um prisioneiro político que foi lançado ao mar atado a um dormente. Assim, o filme nos apresenta uma nova forma de extermínio.

Tais cidadãos exterminados, foram classificados como inimigos internos, pois se colocaram politicamente contrários as medidas autoritárias do governo militar instaurado, pois representavam um atraso ao desenvolvimento econômico do país, uma afronta aos ideais da civilização cristã ocidental e, por isso, deveriam ser eliminados.

Ambos os extermínios podem ser comparados - tanto os dos povos da Patagônia como os ocorridos durante a ditadura militar. A comparação nos mostra que havia interesses econômicos na realização de tais práticas, pois, segundo Quijano:

Por outro lado, no processo de constituição histórica da América, todas as formas de controle e de exploração do trabalho e de controle da produçãoapropriação-distribuição de produtos foram articuladas em torno da relação capital-salário (de agora em diante capital) e do mercado mundial. (Quijano, 2005: 228).

Utilizando uma narrativa poética, o filme costura as histórias dos povos nativos remanescentes daquele território, associando-as com um período da 
história chilena contemporânea. Essas narrativas também podem dialogar com os caminhos trilhados pela América Latina nos últimos 500 anos, e nos convidam a pensar sobre o continente onde vivemos, mas que pouco conhecemos. Conforme citação do crítico de cinema Caetano:

[...] sendo um filme chileno, é a partir de seu território que o diretor abre o horizonte para o mundo. É curioso como em pouco tempo notamos que as histórias dos países latino-americanos são semelhantes, mas desconhecidas entre si. Temos uma educação que nos ensina detalhes da formação dos estados europeus, suas etnias, desenvolvimento, etc., enquanto nossos vizinhos são reduzidos à América espanhola, fragmentada ao longo dos séculos.

Enquanto tribos europeias são diferenciadas para nos explicar dominações e alianças que originaram os países que conhecemos, na América a generalização de índios coloca todas as etnias no mesmo bojo, como uma espécie exótica dizimada em maior ou menor quantidade, conforme a região. (Caetano, 2016).

Nota-se, dessa forma, que nossa formação é eurocêntrica, baseada na matriz europeia como um modelo a ser seguido em detrimento das populações nativas. Vale lembrar que o nome dado à América Latina foi uma forma de silenciar as culturas ameríndias e africanas aqui presentes, uma vez que a latinidade europeia também se impôs ao nome dessa parte do continente americano.

O documentário pode ser visto, então, como uma forma de resgatar e manter viva a memória chilena, pois a memória tende a ser construída e enquadrada de acordo com os acontecimentos que a História oficial julga pertinentes. É nesse sentido que deve-se manter viva não somente a memória nacional mas também a memória subterrânea, muitas vezes representada nos que foram silenciados pela História oficial. Todorov (1995) afirma: "o passado não tem direitos em si, deve ser colocado a serviço do presente, assim como a memória deve-se manter". Nota-se, assim, que o filme documentário aqui discutido traz à tona a memória de um povo - vozes de grupos que foram silenciados pela visão dominante da História.

Vale aqui citar uma frase transcrita após o golpe militar de 1973 no interior do Estádio Nacional do Chile em Santiago, "Um povo sem memória é um povo sem futuro". Este local foi palco de atrocidades da ditadura militar e considerado o primeiro campo de concentração daquele governo ditatorial.

A citação a seguir exemplifica as relações entre cinema e História e discute como um documentário pode alertar para nossa realidade, trazendo elementos que colaboram para uma nova interpretação de mundo:

Durante a colonização da América, nos séculos XVI e XVII, os espanhóis desrespeitaram a cultura e a terra de inúmeras pessoas nativas da região chilena, da região que faz fronteira com o Oceano Pacífico, além de matá-las ou escravizá-las em diversos casos. Uma história marcada pela dominação 
agressiva e violenta persegue a América Latina. Vivemos momentos parecidos no Brasil, se não idênticos: também fomos vítimas do colonialismo, do imperialismo, de momentos marcados pelo autoritarismo. E um povo que não é capaz de preservar sua memória não tem futuro, Patrício Guzmán nos assegura uma coisa: as águas não permitirão que nos esqueçamos nosso passado. (Claudino, 2016).

Desse modo, o papel desse filme documentário é questionar os atores da História oficial, problematizar a espoliação a que o continente americano foi submetido no processo de colonização europeia, bem como criticar as formas de extermínio implementadas durante a ditadura militar chilena, colaborando para uma reinterpretação da História da América Latina.

Destarte, ao mesmo tempo que o cinema pode ser visto como resultado da indústria cultural, essa arte também pode representar uma forma de satisfazer as carências da ordem do imaginário, sendo, então, um meio de democratizar conhecimentos sobre fatos históricos.

\section{Comentários finais}

O botão de pérola faz um resgate das memórias em suas diversas esferas, pois, segundo Pollack (1988: 4), "Ao privilegiar a análise dos excluídos, dos marginalizados e das minorias, a história oral ressaltou a importância de memórias subterrâneas que, como parte integrante das culturas minoritárias e dominadas, se opõem à memória nacional".

Depreende-se, assim, que a memória é um espaço de poder, de disputas políticas por grupos divergentes, tal qual esse filme documentário apresenta - o resgate de conflitos entre grupos antagônicos que marcaram a história do Chile.

O olhar do diretor Patricio Gusmán sobre a produção cinematográfica evidencia que esse cinedocumentário possui um compromisso crítico com a sociedade nele retratada, como observa-se na crítica de Cardinale:

Para Guzmán, el cine documental forma parte de la conciencia critica y analítica de uma sociedad. No puede verse solamente como uno entre lós diferentes gêneros del cine; Es una verdadeira vocación que exige una entrega total y una clara posición ética. (Cardinale, 2010: 10).

A importância da manutenção da memória é associada aos autores póscoloniais que foram aqui citados, uma vez que eles propõem um novo direcionamento do pensar, que questione tanto o conceito de modernidade quanto o modelo mundial do saber que foi imposto e disseminado por intermédio do padrão hegemônico europeu e estadunidense. Realizando uma revisão dessa matriz será possível organizar novas versões, com novos modelos, valendo-se 
da valorização da História dos povos deste continente, outrora silenciados e inferiorizados. Como se observa nas palavras de Mignolo:

Las teorías críticas descoloniales emergen de las ruinas de los lenguajes de las categorías de pensamiento y de las subjetividades (árabe, aymará, hindi, créole, francesa e inglesa en el Caribe, afrikaan, et-cétera) que han sido constantemente negadas por la retórica de la modernidad y la aplicación imperial de la lógica de la colonialidad. (Mignolo, 2010: 27).

A importância da valorização do conhecimento local foi negada pela modernidade, uma vez que esta se apresenta como um dogma. Embora sejam formadas diversas visões sobre a modernidade, em geral mais celebrativas do que sombrias, seus traços mais destacados, seriam o avanço do pensamento científico, da razão instrumental que separa o objetivo e o simbólico, da secularização e da doutrina do progresso; a primazia do individualismo; a afirmação da economia de mercado e do aparelho estatal (Azevedo, 2009: 12).

Esses traços da modernidade são tratados em vários momentos do documentário - como a sobreposição das culturas nativas pelas europeias e pelo silenciamento de opositores durante o regime militar para imposição de um novo modelo econômico.

Por fim, o documentário $O$ botão de pérola, ao ser analisado juntamente com os teóricos pós-colonialistas, apresenta elementos que podem ser utilizados para criticar a mentalidade colonizada dos latinos-americanos que, infelizmente, ainda persiste em muitos de nós.

\section{Referências bibliográficas}

Andrade, M. de. (2009). Poemas para liberdade. São Paulo: Escrituras Editora.

Anderson, P. (1995). O balanço do neoliberalismo. In E. Sader \& P. Gentili (orgs.), Pós-neoliberalismo: as políticas sociais e o estado democrático. Rio de Janeiro: Paz e Terra.

Azevedo, C. (coord.) (2009). Outras modernidades: textos e propostas, vol.1. Nuestra América e EUA. Rio de Janeiro: Editora FGV, 1 CD-ROM.

Benjamin, W. (1994). A doutrina das semelhanças. In __, Magia e técnica, arte e política: ensaio sobre literatura e história da cultura. Trad. S. P. Rouanet. 7. ed. São Paulo: Brasiliense.

Capelato, M. H.; Morettin, E. \& Napolitano, M. (orgs.). (2007). História e cinema: dimensões históricas do audiovisual. São Paulo: Alameda.

Cardinale, C. R. (2010). El cine documental según Patricio Guzmán. 2. ed. Santiago. 
Dinges, J. (2005). Os anos do Condor: uma década de terrorismo internacional no cone sul. São Paulo: Companhia das Letras.

Emperaire, J. (2002). Los nómades del mar. Santiago: Lom ediciones.

Ferreira, R. de A. (2008). Cinema memória: reflexões sobre a memória coletiva e o saber histórico. O Olho da História, (11), dez.

Lira, F. R. F. T. de. (2010). Do socialismo ao neoliberalismo: o Chile dos anos 1970. Vitrine da Conjuntura, 3 (6), ago. Curitiba.

Mignolo, W. D. (2003). Histórias locais projetos globais: colonialidade, saberes subalternos e pensamento liminar. Belo Horizonte: UFMG.

Mignolo, W. D. (2010). Desobediência epistémica: retórica de la modernid, lógica de la modernidad y gramatica de la descolonidad. Buenos Aires: Ediciones Del signo.

Nichols, B. (2005). A voz do documentário. In F. P. Ramos (org.), Teoria contemporânea do cinema, vol. II. São Paulo: Senac.

Pollak, M. (1989). Memória, esquecimento, silêncio. Estudos Históricos, 2 (3), Rio de Janeiro.

Quijano, A. (2005). Colonialidade do poder, eurocentrismo e América Latina. In E. Lander (org), A colonialidade do saber: eurocentrismo e ciências socias. Perspectivas latino-americanas. Buenos Aires: Colección Sur Sur, Clacso.

Sanchéz, G. (2001). La caravana de la muerte: las víctimas de Pinochet. Barcelona: Blume Contrapunto.

Santos, C. L. M. dos. (2011). Cinema, linguagem e educação: articulações e estratégias de significação. Educação, Gestão e Sociedade, ano 1, (2), jun. Faculdade Eça de Queiros. ISNN 2179-9636.

Tapia, J. A. (1980). El terrorismo de estado e el la doctrina de la seguridad nacional em el cono sur México. Editora Nueva Imagem. Disponível em: www.blest.eu/biblio/tapia2/index.html

Todorov, T. (1995). Los abusos de la memória. Barcelona: Ediciones Paidós Ibérica.

Villaça, L. M. (2015). Nostalgia da luz (2010) e o filme-ensaio: uma proposta de análise a partir da trajetória cinematográfica de Patricio Guzmán. Dissertação - Universidade de São Paulo, Escola de Comunicação e Arte da USP. 


\section{Sites}

Claudino, J. O botão de pérola (crítica). Disponível em: www.ccine10.com.br/ o-botao-de-perola-critica/

http://revistapreview.com.br/critica/o-botao-de-perola-mortos-desenterrados/

www.elmostrador.cl/cultura/2015/10/16/critica-de-cine-el-boton-de-nacar-una -metafora-sobre-el-origen-y-la-infamia/

http://cinechile.cl/pelicula-3014

www.patricioguzman.com/es/

\section{Filmografia}

Nostalgia da luz (2010), de Patricio Guzmán.

El botón de Nácar (2015), de Patricio Guzmán.

Vênus negra (2010), de Abdellatif Kechiche. 